\title{
Interim Progress Report - Geophysics: Building E5481 Decommissioning, Aberdeen Proving Ground
}

by M.D. Thompson, M.G. McGinnis, L.D. McGinnis, and S.F. Miller

Reclamation Engineering and Geosciences Section, Energy Sysiems Division,

Argonne National Laboratory, 9700 South Cass Avenue, Argonne, Illinois 60439

November 1992

Work sponsored by United States Army, Aberdeen Proving Ground, Maryland 
This document is printed on recycled paper with the exception of color reproductions. 


\section{Preface}

This report is one of a series on geophysical surveys around perimeters of buildings in the Canal Creek and Westwood areas of the Edgewood section of Aberdeen Proving Ground. The series was initiated in 1991 at Building E5032, where geophysical techniques were tested and a design for the surveys was established. The series continued in 1992, when surveys of Buildings E5190, E5282, E5375, E5440, E5476, E5481, E5485, E5487, E5489, E5974, and E5978 were completed. The surveys and reports were done sequentially, with lowest building numbers being completed first. For this reason, deeper insight into the magnetic, electrical, and radar imagery characteristics of the Canal Creek area was gained with progressively increasing building numbers. A survey at the Building 103 Dump, also completed during the spring of 1992, was not specifically designed to assist building decommissioning, but it is included in the series because it was conducted by our geophysics team using techniques and procedures identical to those for the building decommissioning surveys. 


\section{Contents}

Abstract................................................................................ 1

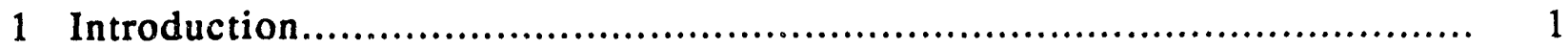

1.1 History of Building E5481 ................................................ 3

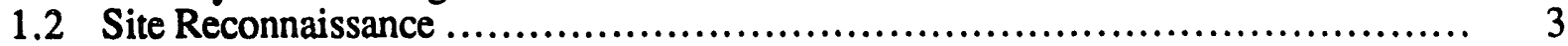

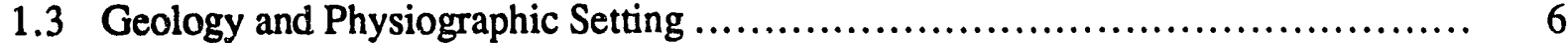

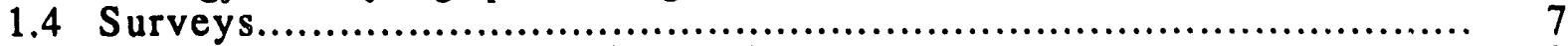

1.5 Survey Grid and Locations of Observations $\ldots \ldots \ldots \ldots \ldots \ldots \ldots \ldots \ldots \ldots \ldots \ldots \ldots, \quad 8$

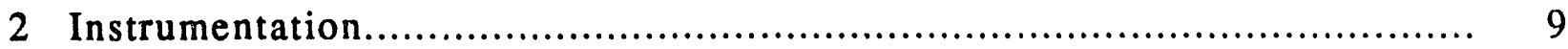

2.1 Magnetic Gradiometer and Cable Locator ........................................ 9

2.2 Magnetometer/Gradiometer...................................................... 9

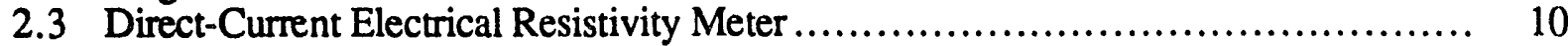

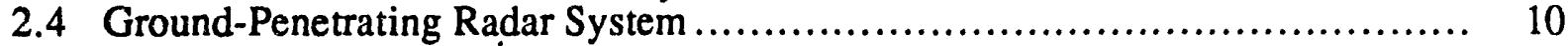

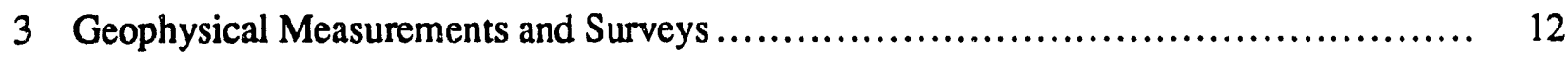

3.1 Magnetometer Measurements.............................................. 12

3.2 Direct-Current Electrical Resistivity Measurements............................. 12

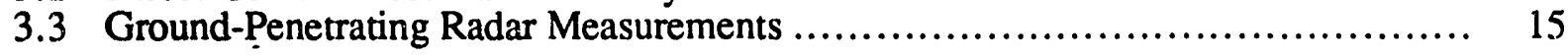

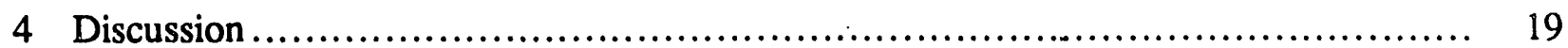

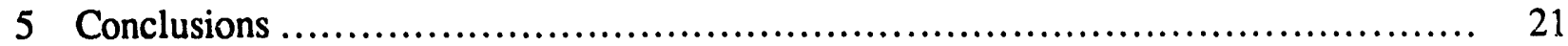

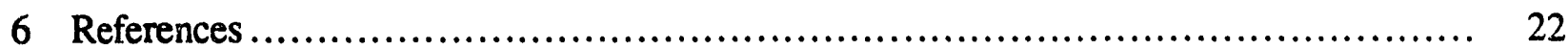

Appendix A: Electrical Depth-Sounding Curves.................................... 23

Appendix B: Ground-Penetrating Radar Line Coordinates $\ldots \ldots \ldots \ldots \ldots \ldots \ldots \ldots \ldots \ldots \ldots . \quad 31$

\section{Tables}

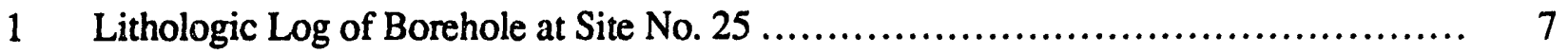

2 Approximate Two-Way Travel Times for Various Materials......................... 11

A.1 Location of Centers of Stations and Orientations of Electrode Arrays for Schlumberger Electrical Depth Soundings at APG ................................ 25

A.2 Resistivity Models Calculated from Electrical Depth Soundings......................... 26 


\section{Figures}

1 General Site Map of the Canal Creek Area, Aberdeen Proving Ground, Md. ............ 2

2 General Location Map of Building E5481 .................................... 4

3 Geophysical Survey Boundaries for Building E5481 ............................. 5

$4 \quad$ Map of Total Magnetic Field Intensity for Building E5481..................... 13

5 Apparent Resistivity Map of Building E5481 ................................. 14

6 West-East Ground-Penetrating Radar Profile for the Area East of Building E5481 ..... 16

7 South-North Ground-Penetrating Radar Profile for the Area East of

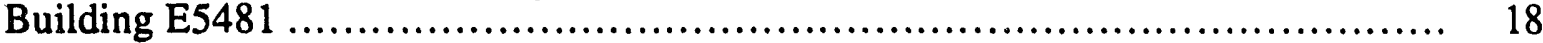

8 Magnetics/Reșistivity Overlay Map of Building E5481 ............................ 20

A.1 Electrical Depth-Sounding Curve near Building E5282............................... 27

A.2 Electrical Depth-Sounding Curve near Building E5440................................. 28

A.3 Electrical Depth-Sounding Curve near Building E5481,.............................. 29

A.4 Electrical Depth-Sounding Curve near Building E5974 ............................... 30 


\title{
Interim Progress Report - Geophysics: Building E5481 Decommissioning, Aberdeen Proving Ground
}

\author{
by \\ M.D. Thompson, M.G. McGinnis, \\ L.D. McGinnis, and S.F. Miller
}

\begin{abstract}
Building E5481 is one of ten potentially contaminated sites in the Canal Creek and Westwood areas of the Edgewood section of Aberdeen Proving Ground examined by a geophysical team from Argonne National Laboratory in April and May of 1992. Noninvasive geophysical surveys, including magnetics, electrical resistivity, and ground-penetrating radar, were conducted around the perimeter of the building to guide a sampling program prior to decommissioning and dismantling. The building is located on the northern margin of a landfill that was sited in a wetland. The large number of magnetic sources surrounding the building are believed to be contained in construction fill that had been used to raise the grade. The smaller anomalies, for the most part, are not imaged with ground radar or by electrical profiling. A conductive zone trending northwest to southeast across the site is spatially related to an old roadbed. Higher resistivity areas in the northeast and east are probably representive of background values. Three high-amplitude, positive, rectangular magnetic anomalies have unknown sources. The features do not have equivalent electrical signatures, nor are they seen with radar imaging.
\end{abstract}

\section{Introduction}

Aberdeen Proving Ground (APG), in the state of Maryland, is currently managing a comprehensive Installation Restoration Program involving more than 360 solid-waste managing units contained within 13 study areas. The Edgewood section and two landfills in the Aberdeen area appear on the National Priority List under the Comprehensive Environmental Response, Compensation, and Liability Act. Therefore, APG has entered into an Interagency Agreement with the U.S. Environmental Protection Agency to address the listed areas.

The West Branch of the Canal Creek area (Figure 1), located within the Edgewood section, is one of the areas that requires a Source Definition Study because there is an ongoing release of volatile organic compounds into the creek. A report prepared by EAI Corporation 


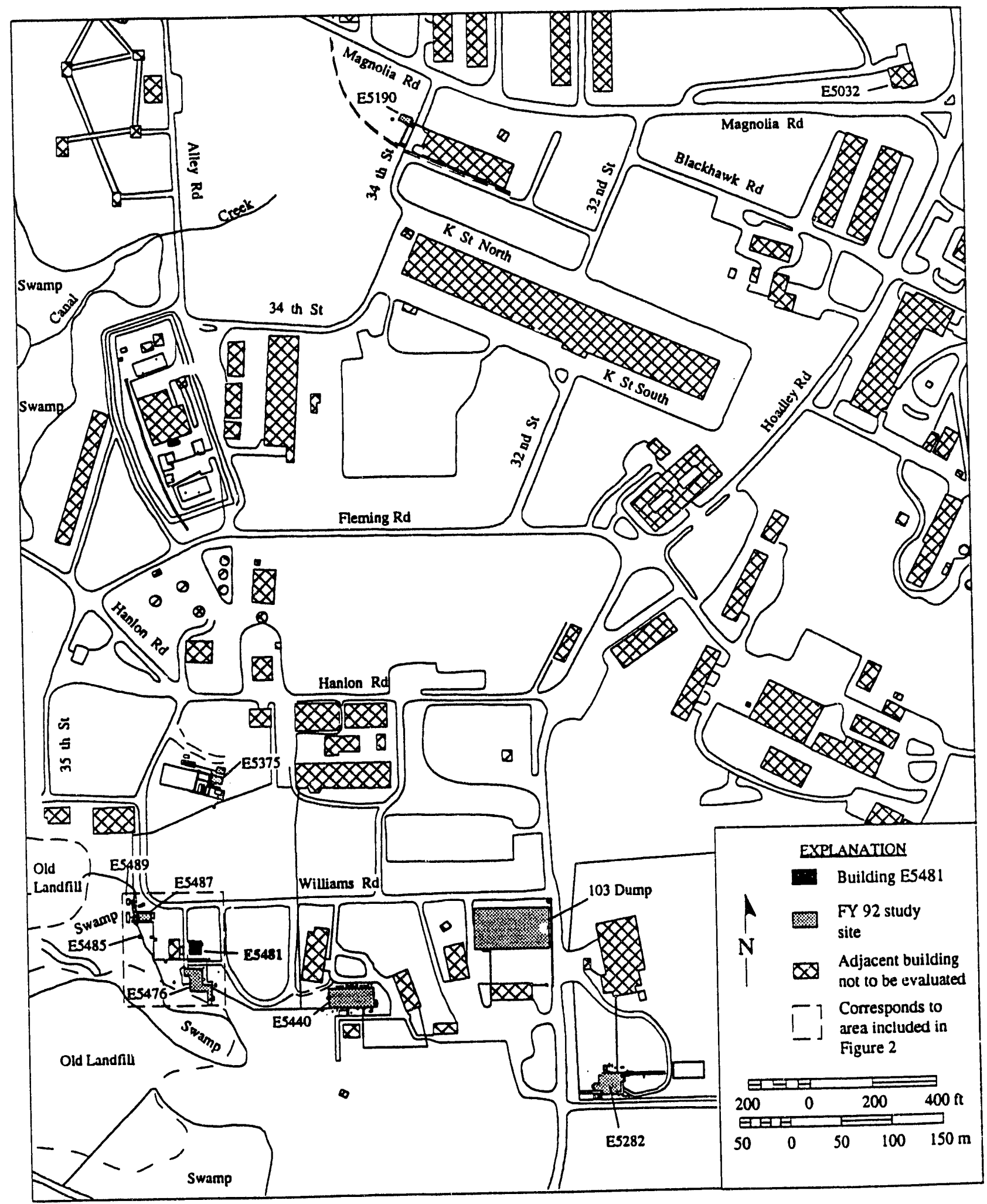

FIGURE 1 General Site Map of the Canal Creek Area, Aberdeen Proving Ground, Md. 
(1989) included a list of 29 potentially contaminated buildings in the Edgewood section. Sixteen of the buildings contain known contaminants, nine buildings contain unknown contaminants, and four of the buildings are potentially clean. The EAI report recommended that a sampling and monitoring program be established to verify contamination levels in and around each building. Thirteen of the potentially contaminated buildings, including Building E5481 (Figure 2), located $120 \mathrm{ft}$ south and near the west end of Williams Road, are in the West Branch of the Canal Creek area and are potential sources of volatile organic compounds. Operations have ceased and the buildings have been abandoned, but processing equipment, sumps, drains, ventilation systems, and underground storage tanks remain. These appurtenances may contain liquid, solid, or vapor contaminants of unknown nature.

Aberdeen Proving Ground is proceeding with a program to decommission the buildings, which will eliminate the actual or potential release of contaminants into the environment of the West Branch of the Canal Creek and other sites within the Edgewood area. Argonne National Laboratory has been assigned the task of developing a plan and scope of work for the proposed decommissioning. Argonne has determined that the first step in this decommissioning process, where it is technically feasible, should be a noninvasive geophysical survey around building exteriors (see Figure 3 for the boundaries of the study area for Building E5481).

\subsection{History of Building E5481}

According to a report on records examined by EAI Corporation (1989), Building E5481 was constructed in 1921 . The two-story structure measures $41 \times 16 \mathrm{ft}$ and is built on a concrete foundation and floor. Walls are made of corrugated metal, and the roof is composed of asphalt shingles. The building was originally used as an experimental plant for the manufacture of diphenylchloroarsine (DA) and went through a series of uses and standbys until 1945, when it was placed on permanent standby. From 1921 until 1945, it was used for the manufacture of DA, monochloracetone, methyl arsenious oxide, and whetlerite. Potential contaminants include copper, ammonia, silver nitrate, chromium oxide, ammonium dichromate, silver azide, silver nitride, pyridine, zinc chloride, and phosphoric acid.

\subsection{Site Reconnaissance}

The geophysical survey program for Building E5481 was designed on the basis of results from a similar study completed between April 8 and April 19, 1991, for Building E5032 (McGinnis and Miller 1991), which is also located in the Canal Creek area (Figure 1). The initial evaluation was further enhanced by a visit to the site in November 1991 and by inspection of aerial photos. The building is located on level terrain $100 \mathrm{ft}$ north of a former wetland and landfill that is covered with tall grass. The grounds are well-maintained, providing good access. Two other buildings, one to the west and one to the south, limited the outer margins of the survey. 


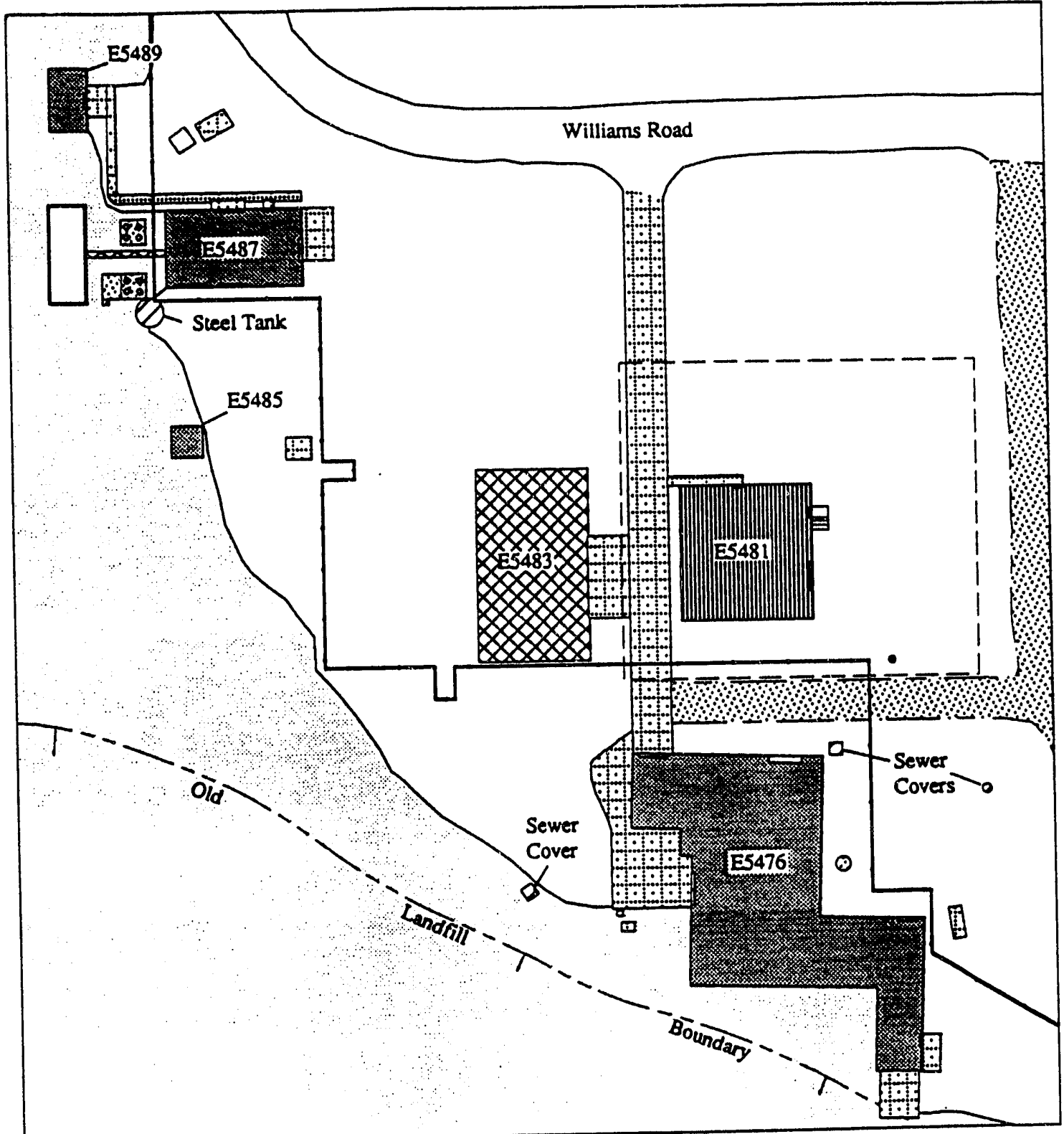

EXPLANATION

\begin{tabular}{|c|c|c|c|}
\hline$\{|||||| \mid$ & Building E5481 & $\bar{\square}$ & Paved road \\
\hline & $\begin{array}{l}\text { FY } 92 \text { study } \\
\text { building }\end{array}$ & 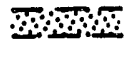 & Gravel road \\
\hline
\end{tabular}

8 Adjacent building not considered in study

Concrete

Area of tall grass and weeds

$T$ Old landrill

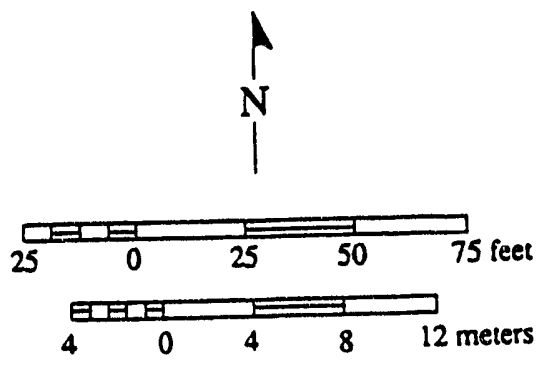

FIGURE 2 General Location Map of Building E5481 


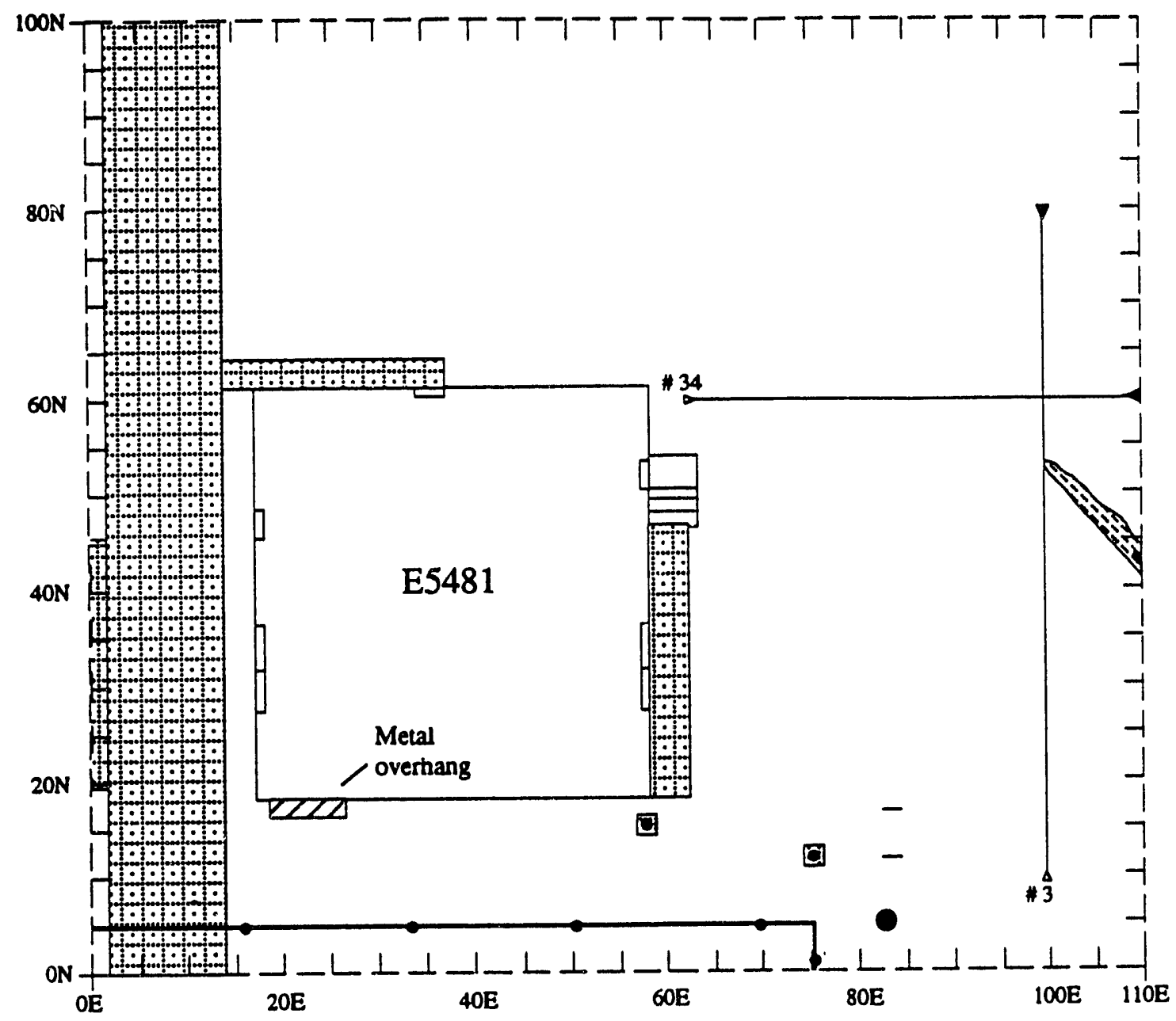

\section{EXPLANATION}

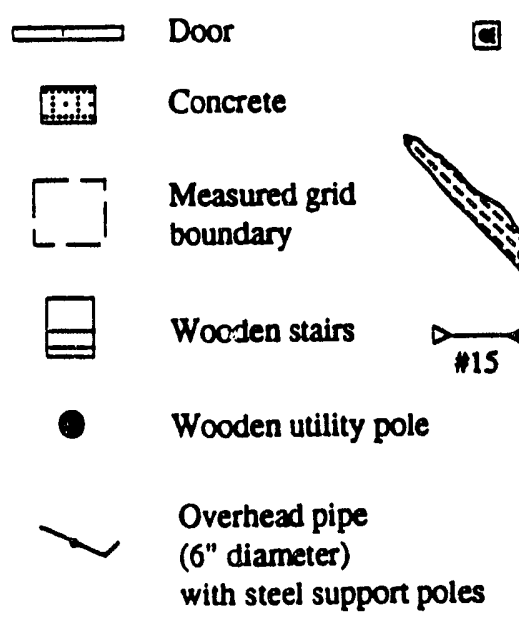

Concrete block with cutoff wooden pole in center

Drainage ditch (ceramic pipe enters at survey boundary)

Ground penetrating radar profile. White triangle is the start of a transect.

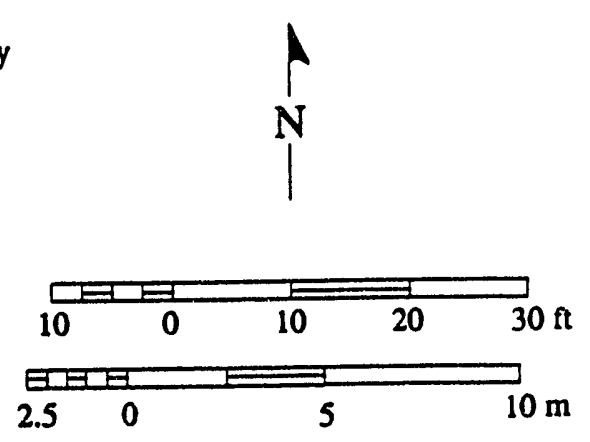

FIGURE 3 Geophysical Survey Boundaries for Building E5481 
In addition to surface conditions at the site, subsurface characteristics were considered in planning the geophysical surveying:

1. Surficial sediments consist of estuarine silts, sands, and clays that have intermediate resistivities and are nonmagnetic. The underlying soil properties are expected to vary both horizontally and vertically in the proximity of the site, depending on naturally occurring conditions and on the presence of building excavations and operations.

2. Buildings and other attributes of the Edgewood section of Aberdeen, such as radio and radar transmissions, will contribute to interference of magnetic and electrical fields and will cause electromagnetic surveying (an easily applied, low-cost method that is frequently used to identify buried conductive objects) to be generally inapplicable (AEHA 1989).

3. Multiple sources, such as iron-rich magnetized objects, nonmagnetic objects, subsurface channels containing contaminants, and plumes of contaminants of variable resistivity, may be present in the subsurface.

Multiple working technologies were utilized in the program design to mitigate interference and to either directly detect or provide inferential data on subsurface characteristics.

\subsection{Geology and Physiographic Setting}

The site is contained in the topographically low and flat terrain of the Coastal Plain physiographic province. The Canal Creek area is underlain by alluvial and estuarine sands, silts, and clays. A thin veneer of sediments of the Talbot Formation of Pleistocene age overlies unconsolidated sediments of the Potomac Group of Cretaceous age (Oliveros and Gernhardt 1989). The water table is less than $10 \mathrm{ft}$ from the surface, and groundwater contains measurable concentrations of contaminants (USGS 1992).

Lithologies at the site were determined from the sample study of a borehole (site No. 25) drilled approximately $150 \mathrm{ft}$ southeast of Building E5481. The descriptive log given in Table 1 was part of a hydrogeologic study of the Canal Creek area performed by the U.S. Geological Survey (Oliveros and Gernhardt 1989). Facies represented include soils and a clayey fill material, followed by thin beds of varying stratigraphy consisting primarily of sands to a depth of $29 \mathrm{ft}$. The single unit of greatest thickness $(10 \mathrm{ft})$ was a tan sand at a depth of 19.0-29.0 ft. This sand is part of the Canal Creek Aquifer (USGS 1992). 
TABLE i Lithologic Log of Borehole at Site No. 25

\begin{tabular}{lcc}
\hline \multicolumn{1}{c}{ Description } & $\begin{array}{c}\text { Depth } \\
(\mathrm{ft})\end{array}$ & $\begin{array}{c}\text { Thickness } \\
(\mathrm{ft})\end{array}$ \\
\hline $\begin{array}{l}\text { Soil zone, brown } \\
\text { Fill material: with brown, [mL-cL] sand, gravel, rock }\end{array}$ & 0.1 & 0.1 \\
fragments, sandstone, asphalt, metal & 7.7 & 7.6 \\
$\begin{array}{l}\text { Sand, light brown-gray, [fL-mU]; with thin, black layer at top, } \\
\text { and clayey, brown silt lense }\end{array}$ & 9.0 & 1.3 \\
$\begin{array}{l}\text { Sand, multicolored, [fU-mU], wet; with irregular banding, and } \\
\text { gray, clayey sand lenses }\end{array}$ & 10.8 & 1.8 \\
$\begin{array}{l}\text { Sand, light yellow-tan, [fU-cL], clean; with sparse light gray } \\
\text { clay lenses }\end{array}$ & 17.0 & 6.2 \\
$\begin{array}{l}\text { No sample } \\
\text { Sand and gravel, purple orange, and tan [mU-cU], silty, } \\
\text { micaceous clay }\end{array}$ & 19.0 & 2.0 \\
$\begin{array}{l}\text { Silt, clayey, and sand, pink and orange-mottled, micaceous; } \\
\text { sand [fL-fU], coarsening downward }\end{array}$ & 29.0 & 5.0 \\
\hline
\end{tabular}

a Codes enclosed in brackets at selected horizons refer to color designations as specified in the Munsell Soil Color Charts (1975).

Source: Oliveros and Gernhardt (1989).

Building E5481 is located near the southern end of the area of study and is adjacent to other buildings not included in the survey. Initial construction probably involved considerable amounts of excavation and use of fill material, so that most of the shallow sediment at the site is reworked.

\subsection{Surveys}

The geophysical phase of the building decommissioning program at Building E5440 was carried out as planned during the period April 6 to May 8, 1992. Geophysical measurements conformed to the work plan (McGinnis et al. 1992), which called for magnetics, horizontal directcurrent electrical resistivity (DCER), and ground-penetrating radar (GPR) surveys. An addition to the plan was the use of a magnetic gradiometer/metal detector to ensure detection of anomalies between survey profiles and grid stations. Seismic imaging information was not required at the site. Each technique had its own specific objectives:

- Gradiometer/metal detector sweep - to provide a rapid, $100 \%$ sweep of the site; 
- Magnetometer measurements - to determine the location of such buried, ironrich objects as tanks, pipes, debris, etc.;

- Horizontal DCER survey - to establish the regional conductive nature of the subsurface and to identify contaminant plumes to depths of approximately $10 \mathrm{ft}$; and

- Ground-penetrating radar survey - to determine the geometry of, and to find the approximate depth to, buried objects.

The following data were acquired during field operations: (1) nonpermanent ground markings of magnetic objects, (2) 1,471 magnetic observations, (3) 407 horizontal DCER observations, and (4) 3,356 (linear) ft of GPR profile along 46 lines. Field operations required three days total for a four-person team. On-site personal computers (both notebook and desktop), interactive software, field equipment designed specifically for Aberdeen, and an all-terrain vehicle were used to expedite data acquisition and processing.

\subsection{Survey Grid and Locations of Observations}

Prior to geophysical surveying, wooden stakes were placed at the site corners to mark the area to be surveyed so that its sides were approximately parallel to the sides of the building. Grid spacing for all surveys was at 5-ft intervals, with the zero coordinate located at the southwest corner of the surveyed area. Positive numbers are meas' 'red north and east of the zero coordinate, whereas negative coordinates are measured south and west. The building is not perfectly aligned north-south and east-west. 


\section{Instrumentation}

\subsection{Magnetic Gradiometer and Cable Locator}

The Schonstedt MAC-51B magnetic gradiometer and cable locator is a dual-mode instrument designed for detecting shallow buried iron and steel objects and tracing underground cables and pipes. The system consists of a transmitter and a dual-function receiver designed to detect anomalous magnetic gradients.

Maps or models are not constructed from observations made with the MAC-51B because it is not a calibrated system. The MAC-51B is an audio device used only ior rapid detection of magnetic materials for further analysis with complementary instrumentation. Anomalies are identified by changes in sound amplitude and frequency and are marked on the ground surface prior to the initiation of other surveys. If anomalies detected with the MAC-51B cannot be verified with the magnetometer (see Section 2.2), the anomaly is assumed to be insignificant.

Application of the MAC-51B in its receiver mode was the first geophysical operation following establishment of survey limits. A qualitative description of the site with $100 \%$ ground coverage is achieved using the gradiometer, whereas the results obtained with other techniques, although more quantitative, are spatially limited to single-point, survey-grid observations or to continuous readings along spaced profiles.

\subsection{Magnetometer/Gradiometer}

Magnetics is the best technique for identifying such buried magnetized objects as tanks, drums, and small iron-rich debris. The EDA OMNI IV magnetometer/gradiometer is a total-field, proton-precession, microprocessor-based instrument that can also measure magnetic gradients. Internal software permits down-loading directly into an on-site computer.

Total-field magnetic observations were made at 5-ft and smaller intervals along profiles, yielding a grid of data that was contoured using the SURFER V. 4.0 software by Golden, Inc. (1991), to identify potential sources of contaminants and to distinguish them from background. The SURFER software was incorporated into the field acquisition procedure, so that daily map outputs were available for observation and interpretation.

The earth's magnetic field is reasonably well-known at a given time and place, although small changes in the field occur continuously, with larger changes occurring during magnetic storms. To adjust for field changes, the instrument has internal calibration to correct observations made at cross lines and base stations. Repeat readings were used to correct data for diurnal field fluctuations. 


\subsection{Direct-Current Electrical Resistivity Meter}

Data on the electrical properties of soils at APG may permit detection of abnormally conductive or nonconductive liquid or solid contaminants. Most of the electrical properties of sedimentary materials are a product of the chemistry of interstitial fluids. Consequently, resistivity data can be diagnostic and complement magnetic and radar measurements. Direct-current electrical resistivity measurements have been incorporated into the APG study to take the place of conductivity measurements typically made for investigations of this type using electromagnetic methods. Electromagnetic methods could not be used because of previously reported interference problems (AEHA 1989).

Resistivity equipment used on the Aberdeen project consisted of an ABEM Terrameter and Booster, model SAS 300C, that utilized a variety of electrode configurations. A modified, eightelectrode Wenner array was the configuration selected, and it was towed behind an all-terrain vehicle. Profiles were coincident with GPR and magnetic lines, and data were recorded at $5-\mathrm{ft}$ intervals along the lines. Consistency of repeat observations over a test profile and over known electrical anomalies provided assurance of relative data quality and variations. Data were contoured using SURFER software as described in the magnetics section.

Electrical depth-sounding curves using a Schlumberger electrode array were also determined in the Canal Creek area to add a three-dimensional view to horizontal mapping. Each sounding curve was interpreted using the RESIX PLUS software package written by Interpex (1988). Resistivities of undisturbed soils were comparable with those observed at Building E5032, which averaged $60 \Omega-m .{ }^{*}$ (See Appendix A for further information.)

\subsection{Ground-Penetrating Radar System}

Ground-penetrating-radar surveying was accomplished using a Geophysical Survey Systems, Inc. (GSSI), model SIR-3 radar connected to a transceiver with a cable approximately $300 \mathrm{ft}$ long. Data were recorded on a digital audio tape to permit playback and computer processing. The control unit/graphic recorder was located in the transport vehicle. An IBMcompatible processing computer was located in a field office, so that the radar operator could down-load, check data-tape quality, and do preliminary processing after a day's run. Radan I computer software written by GSSI was used for processing the GPR data.

Wave-velocity characteristics of materials to be found at the Aberdeen/Edgewood area were derived from known positions of buried objects. Internal calibration was run at least twice each day to ensure that the graphic record of the range setting was consistent. Studies conducted during the 1991 field season suggest wave velocities of 6-7 $\times 10^{-9} \mathrm{~s} / \mathrm{ft}$ for near-surface sediment at

\footnotetext{
* Resistivity data acquisition and processing were done using the metric system of measurement. To convert from meters to feet, multiply values given in meters by 3.28 .
} 
Aberdeen; however, characteristics vary with the heterogeneity of the subsurface. Typical wave velocities for different materials are shown in Table 2.

Ground-penetrating radar is probably the best method available to determine depth and geometry of objects buried near the surface. The weakness of the method is its limited depth of exploration due to wave-propagating constraints imposed by the electrical properties of soils. The maximum depth of penetration with GPR at Building E5481 was approximately $8 \mathrm{ft}$ below the ground surface.

TABLE 2 Approximate Two-Way Travel Times for Various Materials

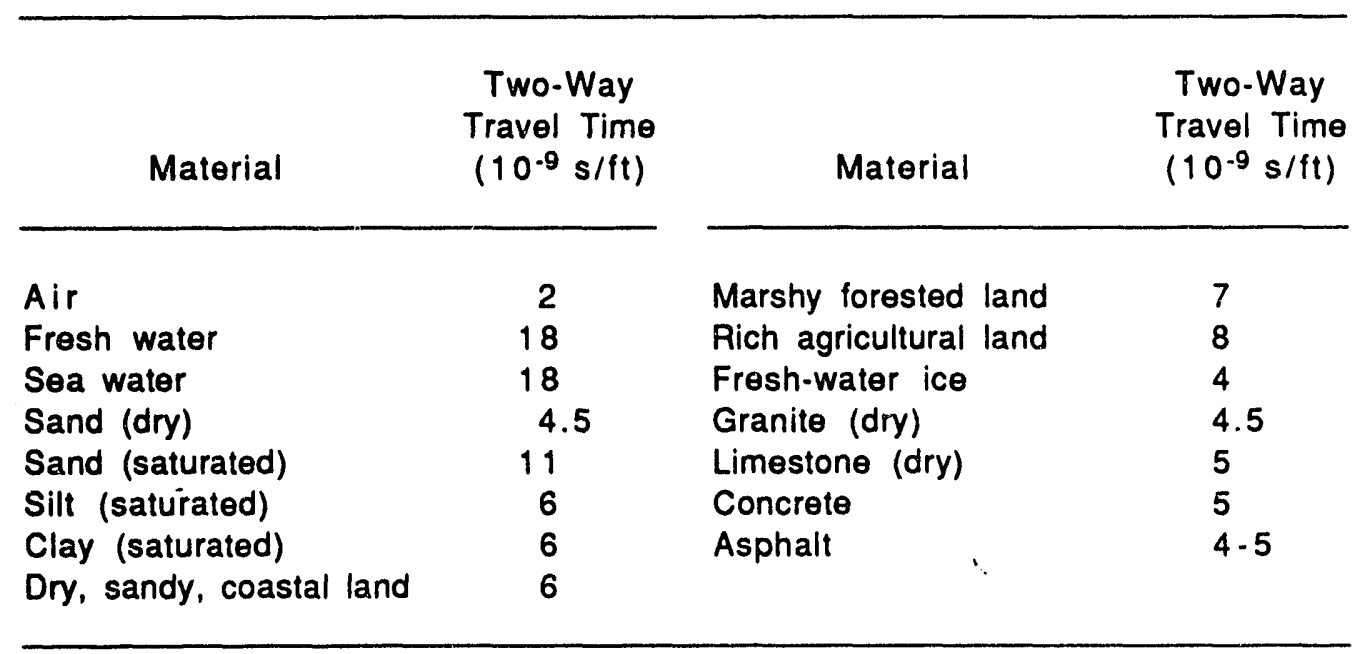

Source: Geophysical Survey Systems, Inc. (1987). 


\section{Geophysical Measurements and Surveys}

\subsection{Magnetometer Measurements}

Total magnetic field observations were made at 1,471 stations for use in constructing the magnetic map shown in Figure 4. Station spacing was normally $5 \mathrm{ft}$; however, where the presurvey gradiometer scan identified anomalous zones, stations were read at intervals as small as $1 \mathrm{ft}$. Magnetic maxima and minima were truncated in order to permit contouring at a smaller interval. This results in a "white-out" effect in the interiors of high-amplitude anomalies and a blackening of anomaly edges where gradients are highest. This procedure enhances the visual identification of anomaly boundaries, while eliminating essentially meaningless detail near peaks and troughs.

A strong magnetic field caused by the corrugated iron walls of Building E5481 distorts or obscures smaller, local anomalies surrounding the building. Although some undulations in magnetic contours near the building are observed, residual magnetic anomalies that might be produced by subsurface objects cannot be distinguished from anomalies having building sources.

Between 20 and 25 unidentified magnetic objects are present around Building E5481. These may be contained in construction fill, as has been observed at other buildings in the Canal Creek area. Because of the building's proximity to the wetlands, it is likely that several feet of fill was required to raise the grade of the surface on which the building was constructed.

Three large, rectangular, magnetic anomalies that are not produced by the corrugated iron walls of the building have centers located at $10 \mathrm{~N}, 75 \mathrm{E} ; 30 \mathrm{~N}, 100 \mathrm{E}$; and $85 \mathrm{~N}, 75 \mathrm{E}$. These anomalies measure $25 \times 10 \mathrm{ft}, 25 \times 5 \mathrm{ft}$, and $15 \times 5 \mathrm{ft}$, respectively. The first anomaly is most likely associated with the concrete block containing a cutoff wooden pole that is located at $10 \mathrm{~N}, 75 \mathrm{E}$ and with the remains of metal hardware at the surface that are associated with the old pole. The other two magnetic anomalies may be produced by concentrated small debris just below the ground surface that appear as one large object.

\subsection{Direct-Current Electrical Resistivity Measurements}

The apparent resistivity map shown in Figure 5 was constructed by using DCER observations made at 407 stations. The electrode spacing was $2 \mathrm{~m}$, a configuration that provides an average resistivity for materials lying between the surface and a depth of about $3 \mathrm{~m}$. At Building E5481, these materials would include construction fill; a brown-to-gray clay, sand, and gravel; and most of the thickness of the Upper Confining Unit (Oliveros and Gernhardt 1989), which is a silty clay. 


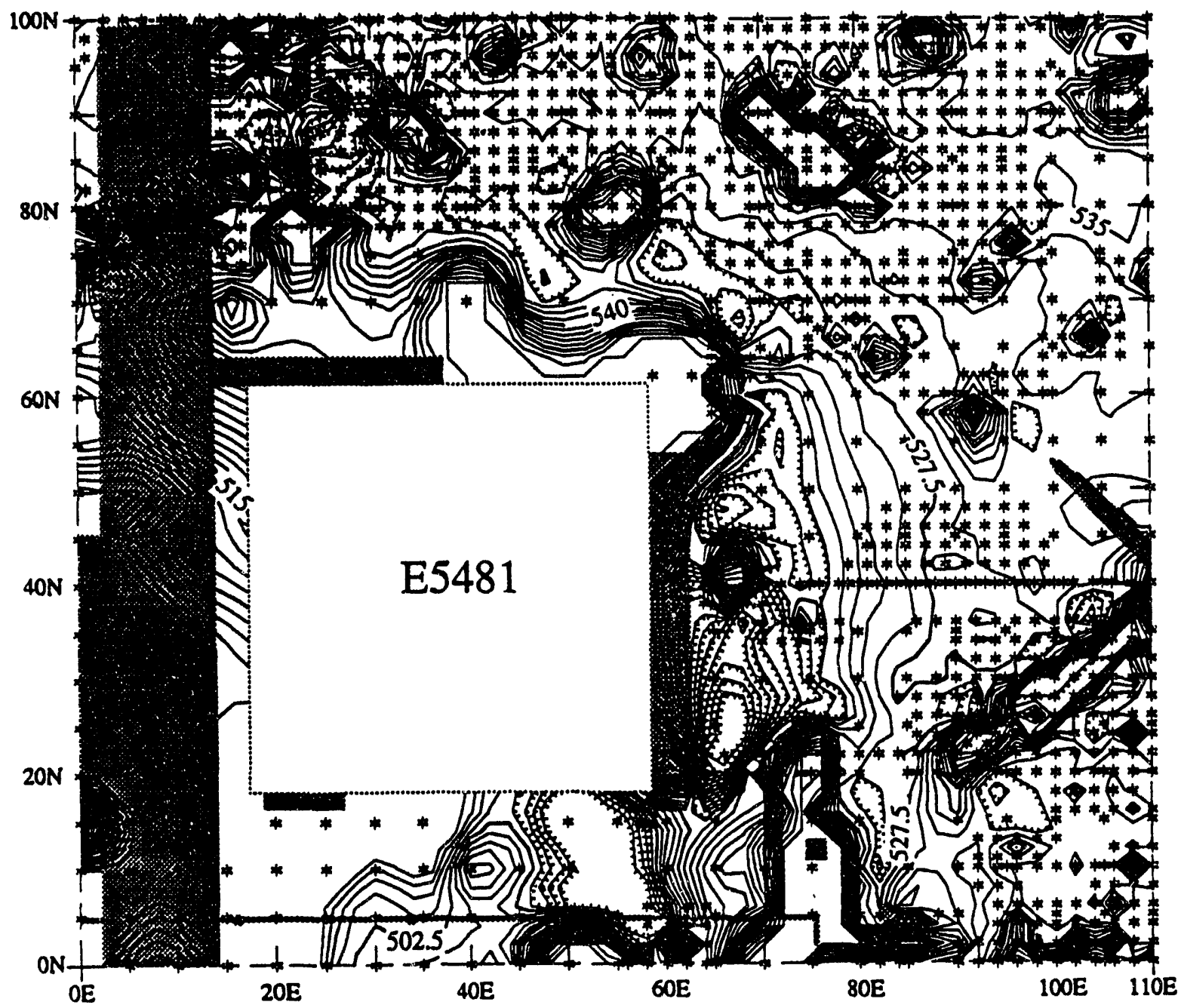

NOTE - Magnetic contours have been overlaid on Figure 3; refer to Figures 2 \& 3 for description of gray areas on this figure.

\section{EXPLANATION}
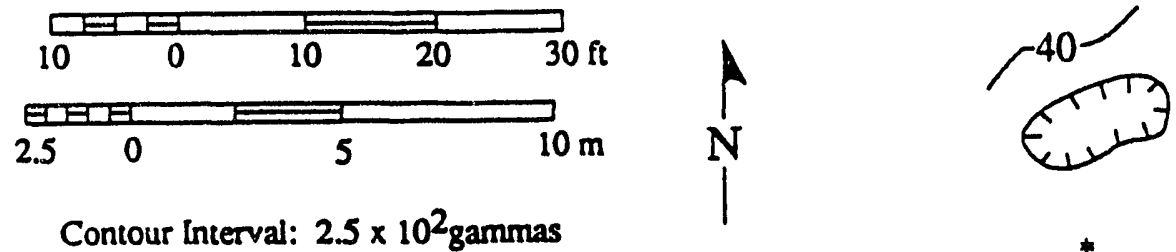

Magnetic contour (hachured areas denote magnetic lows)

Magnetic station

FIGURE 4 Map of Total Magnetic Field Intensity for Building E5481 


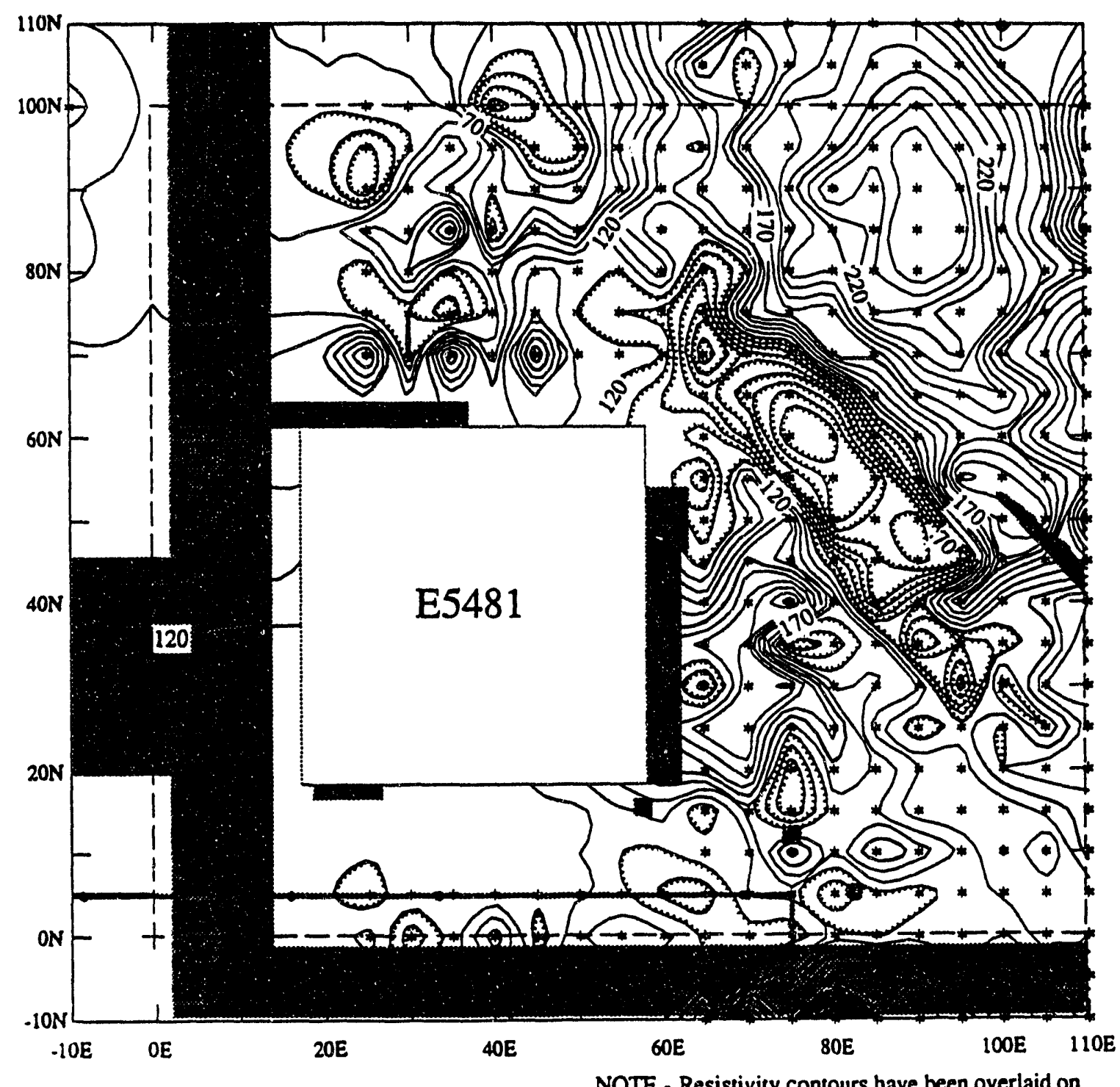

NOTE - Resistivity contours have been overlaid on Figure 3; refer to Figures 2 \& 3 for description of gray areas on this figure.

\section{EXPLANATION}

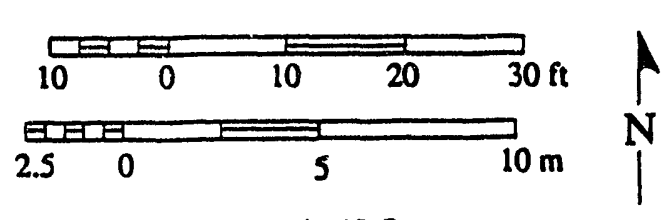

Contour Interval: $10 \Omega \cdot m$

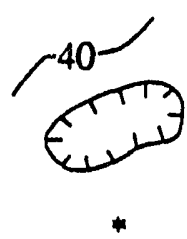

$*$
Resistivity contour (hachured areas denoce

resistivity lows)

Center of electrode array

FIGURE 5 Apparent Resistivity Map of Building E5481 
From previous work (McGinnis and Miller 1991), background resistivities for these finegrained, organic-rich, clayey materials were found to range from 50 to $150 \Omega-\mathrm{m}$. As a basis for comparison with minima observed in other areas, a value of $6 \Omega-\mathrm{m}$ was observed over the "bare spot," a suspected buried tank at Building E5032, and high resistivities of up to $180 \Omega-\mathrm{m}$ were observed in the vicinity of a suspected old railroad bed.

Electrical depth-sounding curves collected for background in the Edgewood area indicate that resistivity values normally decrease with depth, probably due to increasing saturation and salinity. Where anomalous materials are present, this generalization is not valid. An electrical depth-sounding curve measured at a station centered $200 \mathrm{ft}$ north of Building E5481 is shown in Appendix A (see Figure A.3). The sounding station was located in an open, grass-covered field north of Williams Road. Inversion of the curve measured at this station results in an interpreted model where the upper $4.1 \mathrm{~m}$ of earth has a surficial resistivity of $366 \Omega-\mathrm{m}$. From $4.1 \mathrm{~m}$ to the maximum depth of exploration, the average resistivity value of undisturbed material is $105 \Omega-\mathrm{m}$. This resistivity corresponds to a section consisting primarily of sand, as identified on the driller's $\log$ (Table 1), and is representative of undisturbed, natural, saturated materials.

Conductive areas associated with Building E5481 include (1) a northwest-southeast lineament over an old roadbed, striking across the entire area surveyed, immediately north of the northeast corner of the building; and (2) a conductive, north-south lineament along the eastern margin of the survey area that is located over the western edge of a former roadbed. The entire west side of the area mapped appears as a moderately conductive region. However, because of a concrete roadway, very few resistivity readings were made on the west side, and the contouring is an artifact of the Surfer mapping program.

Anomalous resistive areas include (1) a broad, elliptical zone in the northeast quadrant, reaching approximately $240 \Omega-\mathrm{m}$, that may represent background values; and (2) a sinuous feature reaching $200 \Omega-\mathrm{m}$ along the eastern border of the building.

The configuration of resistivity contours observed in Figure 5 is a consequence of human activities. The original overburden, which was deposited in a marginal, wetland environment, has been completely reworked. Some of the activity is related to construction and operation of Building E5481, whereas the remainder is associated with a broad array of operations, including road construction, grade raising, and landfill operations in the Canal Creek area.

\subsection{Ground-Penetrating Radar Measurements}

Ground-penetrating radar measurements around the building perimeter were made at $5-\mathrm{ft}$ intervals over 3,356 ft of traverse along 46 individual profiles, coincident with magnetic and resistivity profiles. The lines are numbered in sequence and are listed in Appendix B, along with the beginning and ending positions relative to the grid. Prior to running the production lines for 


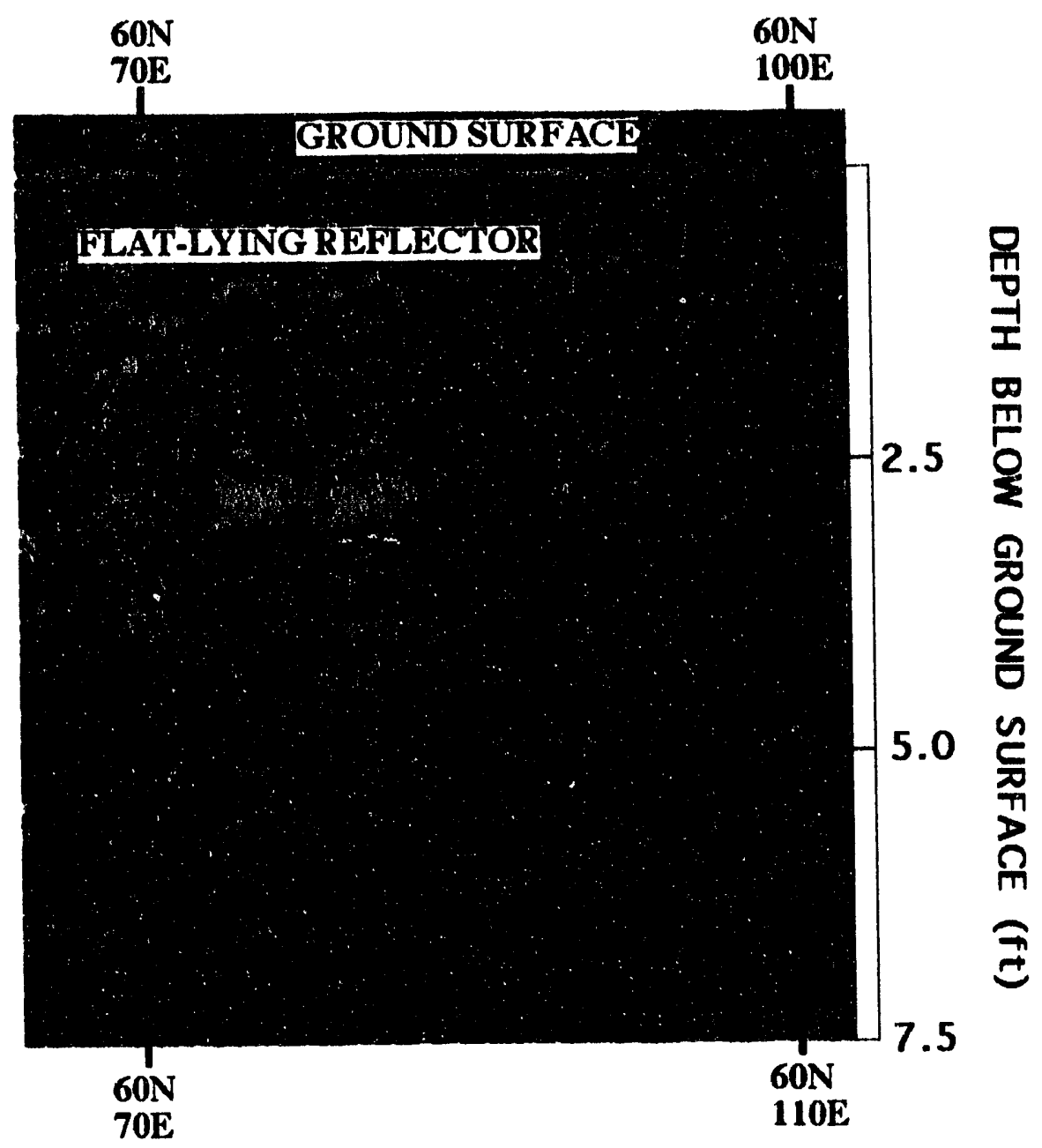

FIGURE 6 West-East Ground-Penetrating Radar Profile for the Area East of Building E5481 (The location of this profile is shown in Figure 3 as line No. 34.)

the survey, replicate runs were made to determine which of the three transceivers - the 80-, 300-, or 500-MHz antenna - was best suited to study the terrain surrounding the site. The transceiver providing the best penetration and resolution of buried objects was the $300-\mathrm{MHz}$ unit. Different range settings were also tested over the same transect to determine the optimum resolution and depth of penetration. A range setting of $90 \mathrm{~ns}$ was used for the entire survey at a scan rate of $16 \mathrm{scans} / \mathrm{s}$. Antennas were pulled by hand at approximately $3 \mathrm{ft} / \mathrm{s}$.

Without verification by another technique or by passing the antenna over a known buried object, characteristics of radar anomalies may only be inferred. However, where anomalies are also seen with magnetic or resistivity profiling, a diagnostic interpretation of the radar anomaly is possible. In the case of Building E5481, good correlation between GPR and resistivity was achieved. However, the GPR did not correlate with the magnetics. This is most likely due to the presence of very small magnetic anomalies that cannot be detected easily with GPR. 
Figures 6 and 7 show GPR profiles collected along the east side of Building E5481. The vertical scale is shown on the right side of the profile, whereas lines are marked at 10-ft intervals on the horizontal scale. Good penetration was observed over most of the site, with resolution down to about $8 \mathrm{ft}$ below the ground surface. The major findings around Building E5481 consist of the following anomalies:

1. The west-to-east GPR profile in Figure 6 shows a shallow, flat-lying reflector centered at coordinates $60 \mathrm{~N}, 80 \mathrm{E}$. This reflector appears to be about $20 \mathrm{ft}$ wide, and the top of the reflector is about $1 \mathrm{ft}$ below the ground surface. A predictive deconvolution was performed on this profile to remove some ringing multiples and enhance the feature of concern. The RCRA Facility Assessment Report for the Edgewood area (AEHA 1989) indicated that a road was formerly sited at the location of this flat-lying reflector. This GPR profile most likely shows the base of the old roadbed or some other portion of the road fill.

2. The south-to-north GPR profile in Figure 7 shows the same flat-lying reflector that is seen in Figure 6. In this profile, the reflector is centered at grid coordinates $35 \mathrm{~N}, 100 \mathrm{E}$. A predictive deconvolution was also performed on this profile to remove some ringing multiples and enhance the feature of concern.

The GPR anomalies that were detected around Building E5481 are most likely associated with road construction, grade raising, and other construction activities. 


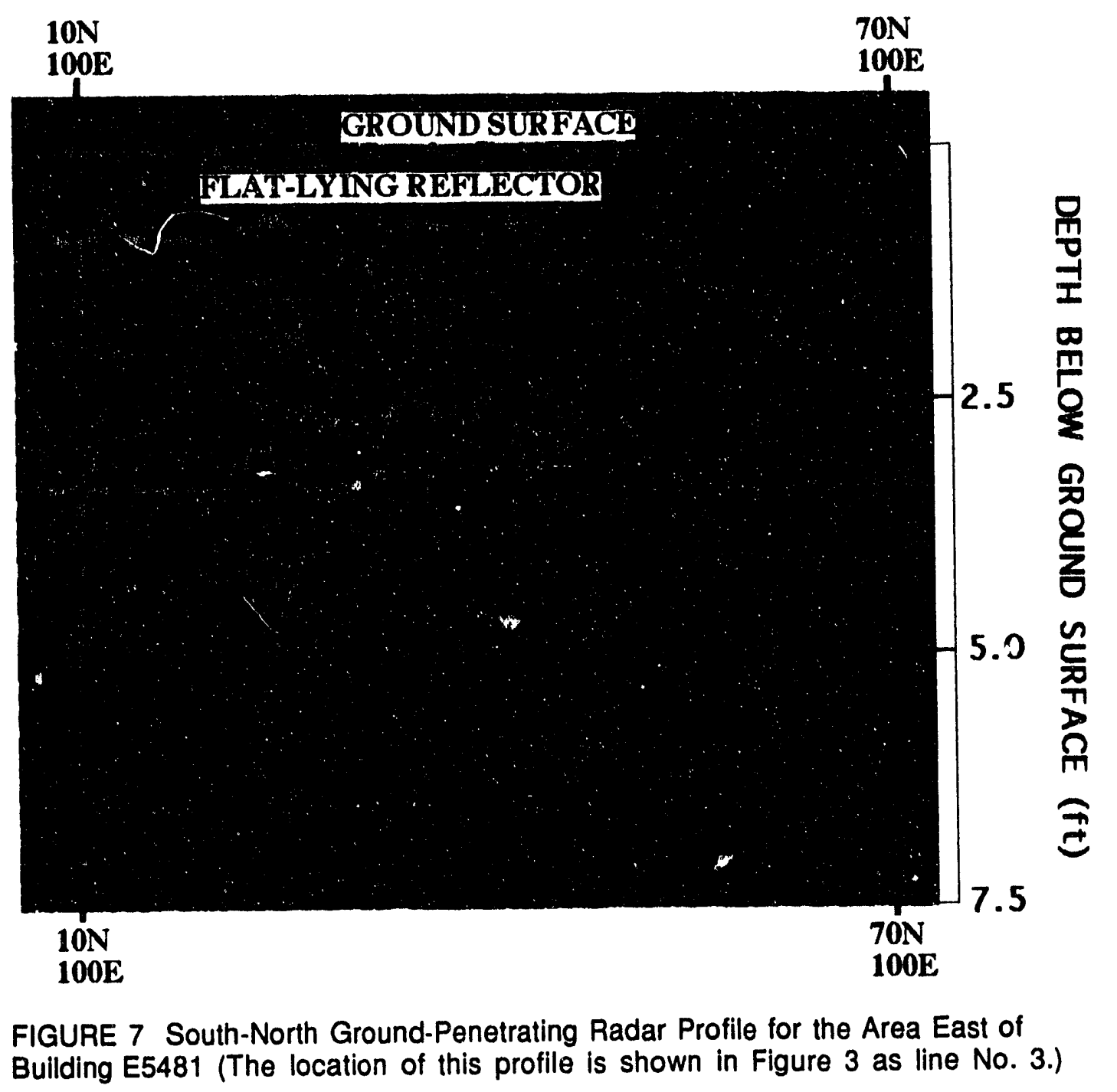




\section{Discussion}

Magnetic and resistivity anomalies are superimposed on a map in Figure 8. The three major magnetic anomalies have no equivalent electrical or GPR anomalies. In fact, the magnetic anomaly centered at $30 \mathrm{~N}, 100 \mathrm{E}$ is orthogonal to the strike of the primary electrical feature on the resistivity map. The larger magnetic anomalies may be associated with an underground stormsewer system, whereas the smaller unidentified magnetic objects may be part of the construction fill. It is uncertain why the larger magnetic anomalies are not seen in either the electrical-field or the GPR profiles; they may be buried deeper than the range of exploration or be very small and located just below the ground surface. The GPR profiles did not reveal any buried objects in or around these three major magnetic anomalies.

The primary electrical anomaly observed in Figure 8 is a high-conductivity zone in the northeast quadrant, occupying the area of a former roadbed. This highly conductive zone is also seen in both the east-west and south-north GPR profiles. A gravelly raised surface observed beneath the grass is spatially associated with the conductive zone, and the existence of a road is mentioned in historical documentation. However, in some of the other areas where the grade has been raised, such as at the old railroad bed at Building E5032, conductivity is low.

The resistive zones located in the northeast quadrant of the site and along the southern half of the east wall of the building may approximate normal background, although the presence of one unidentified magnetic object centered well within the area of low conductivity in the northeast quadrant indicates that the area is not completely "clean." Other unidentified magnetic objects are located on the edges of resistive areas or in conductive belts; these are probably associated with construction fill. 


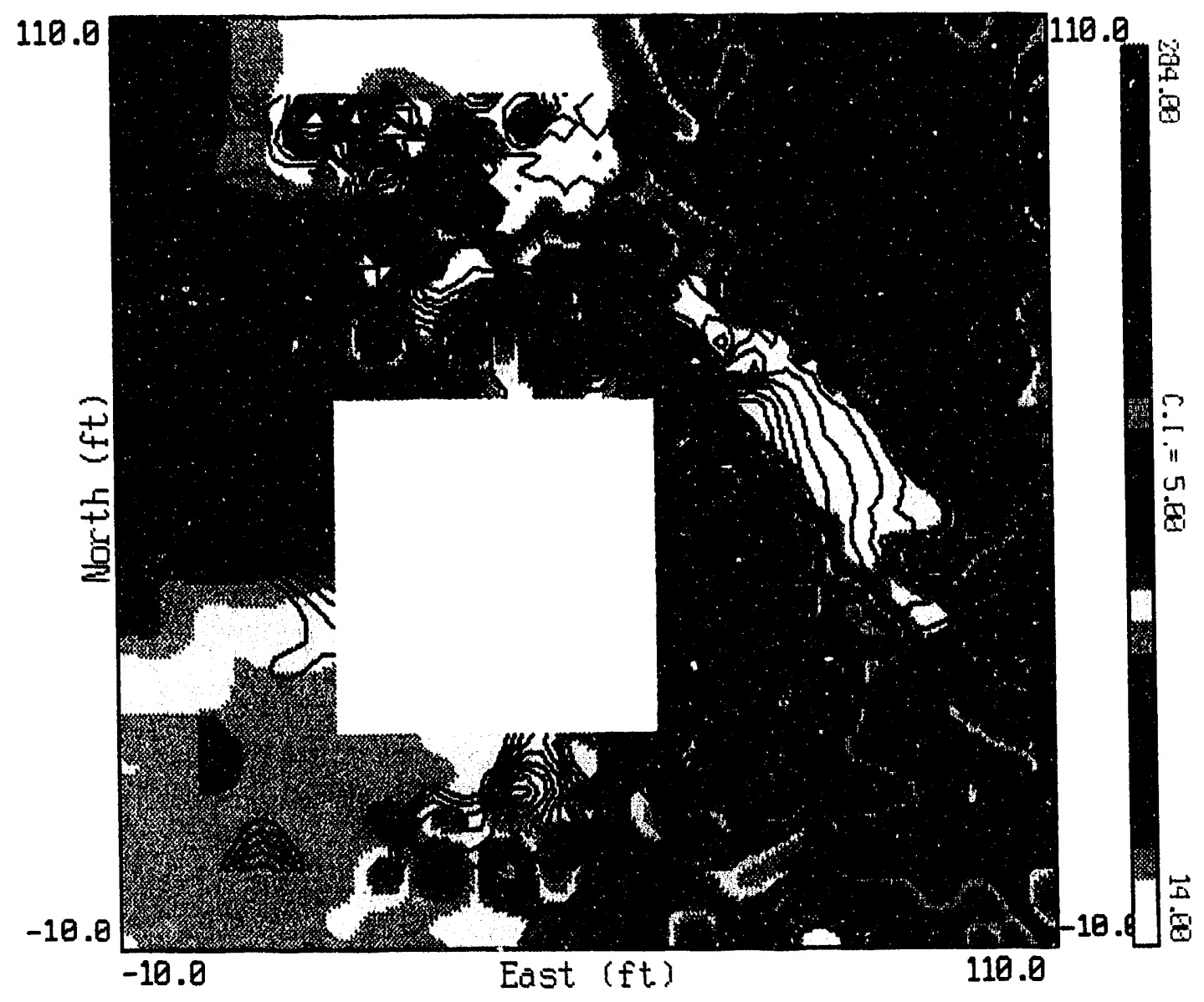

FIGURE 8 Magnetics/Resistivity Overlay Map of Building E5481 


\section{Conclusions}

Specific conclusions drawn from the site surveys arourid Building E5481 are as follows:

1. Smaller magnetic anomalies around the building are believed to be associated with construction fill.

2. Three rectangular magnetic anomalies, having long axes that measure $15-25 \mathrm{ft}$ and short axes of 5-10 ft, in the eastern half of the surveyed area may be associated. with scattered metal debris just below the ground surface. They are not assoriated with electrical anomalies or seen in GPR profiles, and they are all $10 \mathrm{ft}$ or inore from the building.

3. A northwest-to-southeast-trending, low-resistivity lineament in the northeast quadrant is spatially associated with an old roadbed. The construction-fill material used to raise the grade for the roadbed contains materials more conductive than background. The GPR profiles correlate with this highly conductive feature, which is seen as a flat-lying reflector in the upper $1 \mathrm{ft}$.

4. Two high-resistivity zones, one in the far northeastern quadrant and a second immediately east of Building E5481, probably represent background values. 


\section{References}

AEHA: see U.S. Army Environmental Hygiene Agency.

EAI Corporation, 1989, Historical Records Search and Site Survey of Edgewood Area Buildings, Final Report, prepared for U.S. Army Chemical Research, Development, and Engineering Center, Aberdeen Proving Ground, Md., under contract No. DAA15-87-D0021.

Geophysical Survey Systems, Inc., 1987, Operations Manual for Subsurface Interface Radar (SIR System-3).

Golden Software, Inc., 1991, SURFER Version 4, Golden, Colo.

Interpex Limited, 1988, RESIX PLUS User's Manual, Golden, Colo.

McGinnis, L.D., and S.F. Miller, 1991, Interim Progress Report - Geophysics: Building E5032 Decommissioning, Aberdeen Proving Ground, report ANL/ESD/TM-20, Argonne National Laboratory, Argonne, Ill.

McGinnis, L.D., S.F. Miller, M.G. McGinnis, and M.D. Thompson, 1992, unpublished information, Argonne National Laboratory, Argonne, Ill.

Munsell Soil Color Charts, 1975, Macbeth, a division of Kollmorgen Corp., Baltimore, Md.

Oliveros, J.P., and P. Gernhardt, 1989, Hydrogeologic Data for the Canal Creek Area, Aberdeen Proving Ground, Maryland, April 1986-March 1988, U.S. Geological Survey Open-File Report 89-387.

U.S. Army Environmental Hygiene Agency, 1989, RCRA Facility Assessment Report, Edgewood Area, Aberdeen Proving Ground, Maryland.

U.S. Geological Survey, 1992, Contamination of Groundwater, Surface Water, and Soil, and Evaluation of Selected Pumpage Scenarios in ihe Canal Creek Area of Aberdeen Proving Ground, Maryland, draft open-file report.

USGS: See U.S. Geological Survey. 
Appendix A:

Electrical Depth-Sounding Curves 


\section{Appendix A:}

\section{Electrical Depth-Sounding Curves}

Four Schlumberger electrical depth soundings near buildings in the Edgewood area provide a depth dimension to resistivities of soils, sediment, and anomalous unidentified materials. Soundings were made near Buildings E5282, E5440, E5481, and E5974. Locations of centers of stations and orientations of electrode arrays are listed in Table A.1, and the curves are shown at the end of Appendix A as Figures A.1-A.4.

Inversion of these curves using the Interpex code, RESIX PLUS (Interpex Limited 1988), indicates that resistivity of dry soils is from 200 to $300 \Omega-\mathrm{m}$; ${ }^{*}$ saturated sediments, about $100 \Omega$-m; saturated, organic-rich sediments, about $200 \Omega-\mathrm{m}$; and anomalous materials range from less than 10 to $10,000 \Omega-\mathrm{m}$. Maximum current electrode spacings $(\mathrm{AB} / 2)$ ranged from 40 to $100 \mathrm{~m}$, providing information to depths of about $50 \mathrm{~m}$.

Normal undisturbed curves were observed at Buildings E5282 and E5481. These stations were located in topographically low areas where the water table lies within $3 \mathrm{~m}$ of the surface.

A reasonable interpretation of the curve at Building E5440, which was centered in an open area northeast of the building, is not feasible without more historical information about the site. Former roads, landfills, and other subsurface artifacts could explain the orders of magnitude change in resistivity values from $15 \Omega-\mathrm{m}$ to $10,000 \Omega-\mathrm{m}$ at a depth of $11 \mathrm{~m}$.

TABLE A.1 Location of Centers of Stations and Orientations of Electrode Arrays for Schlumberger Electrical Depth Soundings at APG

\begin{tabular}{lcc}
\hline Station Center & $\begin{array}{c}\text { Array } \\
\text { Orientation }\end{array}$ & $\begin{array}{c}\text { Maximum } \\
\text { Electrode } \\
\text { Spacing } \\
(\mathrm{m})\end{array}$ \\
\hline $\begin{array}{l}\text { Northeast of Building E5282 } \\
\text { Northeast of Building E5440 }\end{array}$ & E-W & 50 \\
North of Building 5481 & E-W & 40 \\
Northwest of Building E5974 & NW-SE & 80 \\
\hline
\end{tabular}

* Electrical depth soundings were measured in the unit of $\Omega$-meter. Thus, discussion of electrical depth soundings in this report gives depths measured in meters. To convert from meters to feet, multiply depths in meters by 3.28 . 
The sounding curve at Building E5974 displays the most unusual surface resistivities. A 2.7-m-thick layer of extraordinarily high resistivity $(3,055 \Omega-\mathrm{m})$ near the surface is underlain by a layer having a higher than normal value $(440 \Omega-\mathrm{m})$ extending to a depth of $50 \mathrm{~m}$. This is underlain by a layer having normal resistivities of near $123 \Omega-\mathrm{m}$.

Table A.2.

Earth resistivity models calculated from inversion of the sounding curves are shown in

TABLE A.2 Resistivity Models Calculated from Electrical Depth Soundings

\begin{tabular}{lrcc}
\hline Station & $\begin{array}{c}\text { Resistivity } \\
(\Omega-m)\end{array}$ & $\begin{array}{c}\text { Thickness } \\
(\mathrm{m})\end{array}$ & $\begin{array}{c}\text { Depth } \\
(\mathrm{m})\end{array}$ \\
\hline E5282 & 108 & 0.4 & 0.4 \\
& 244 & 4.5 & $\begin{array}{c}4.9 \\
\text { unknown }\end{array}$ \\
& 95 & unknown & \\
E5440 & 269 & 1.2 & 1.2 \\
& 14 & 10.1 & 11.3 \\
& 11,525 & unknown & unknown \\
E5481 & 366 & 4.1 & 4.1 \\
& 105 & unknown & unknown \\
& & & 0.9 \\
E5974 & 783 & 0.9 & 0.9 \\
& 3,055 & 2.7 & 3.6 \\
& 440 & 46.4 & 50.0 \\
& 123 & unknown & unknown \\
& & & \\
\hline
\end{tabular}



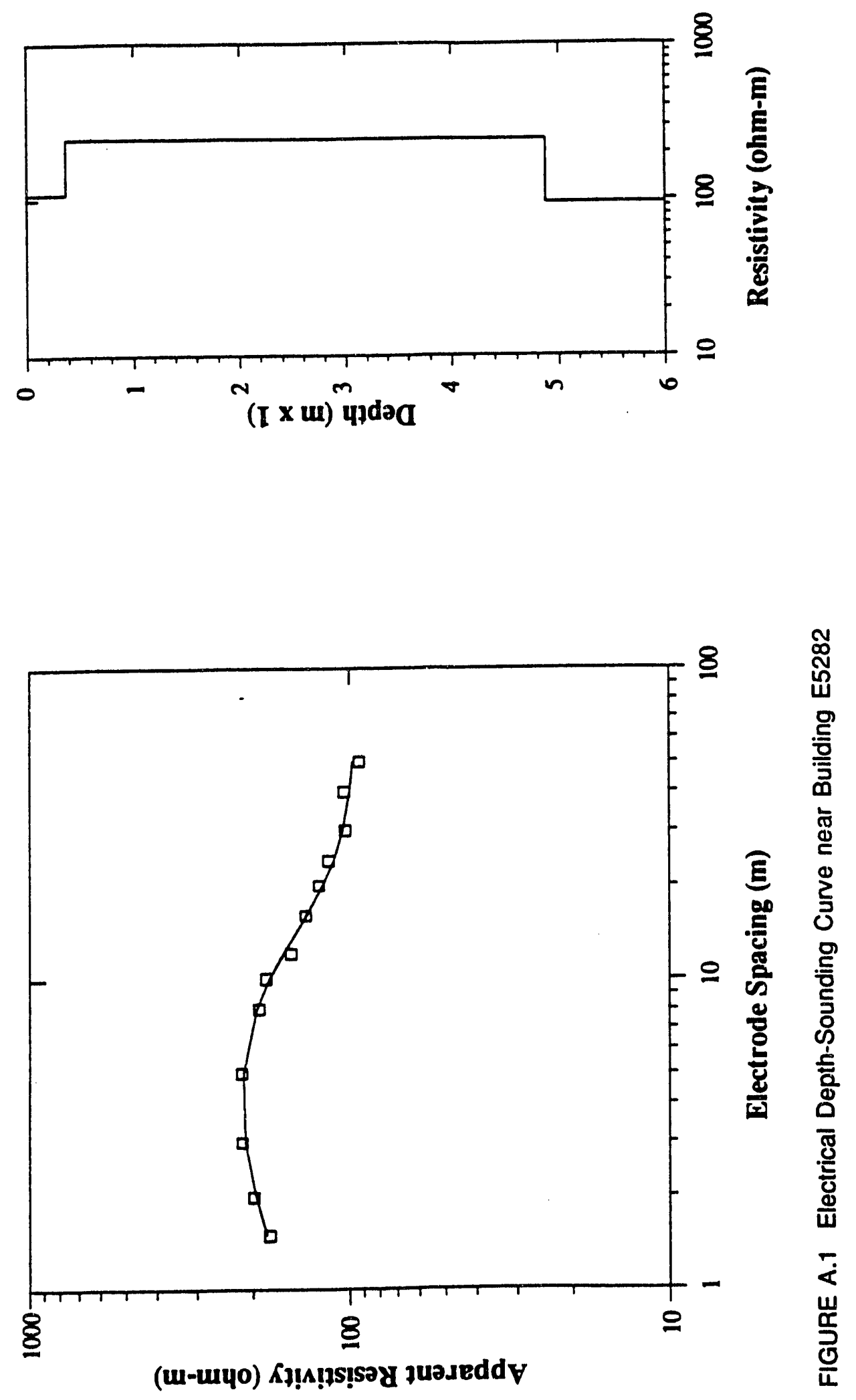


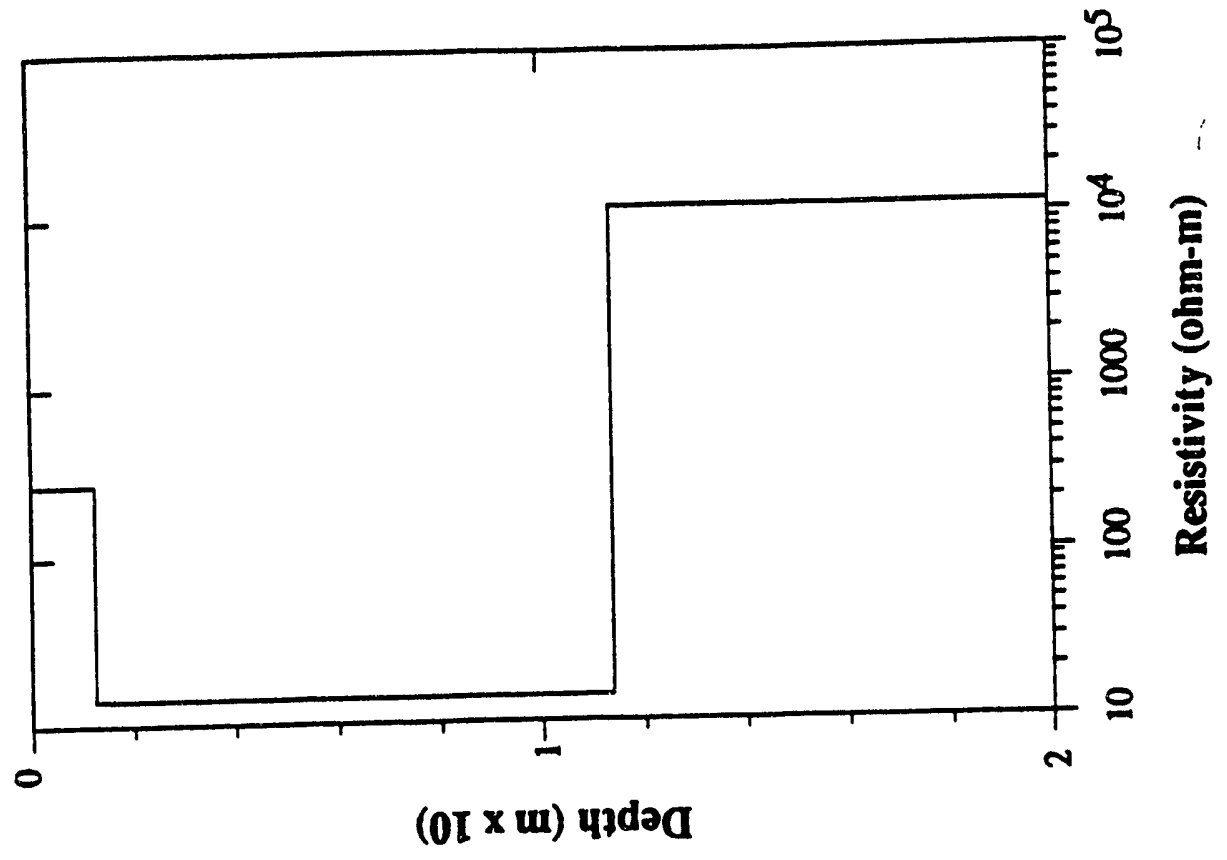

导

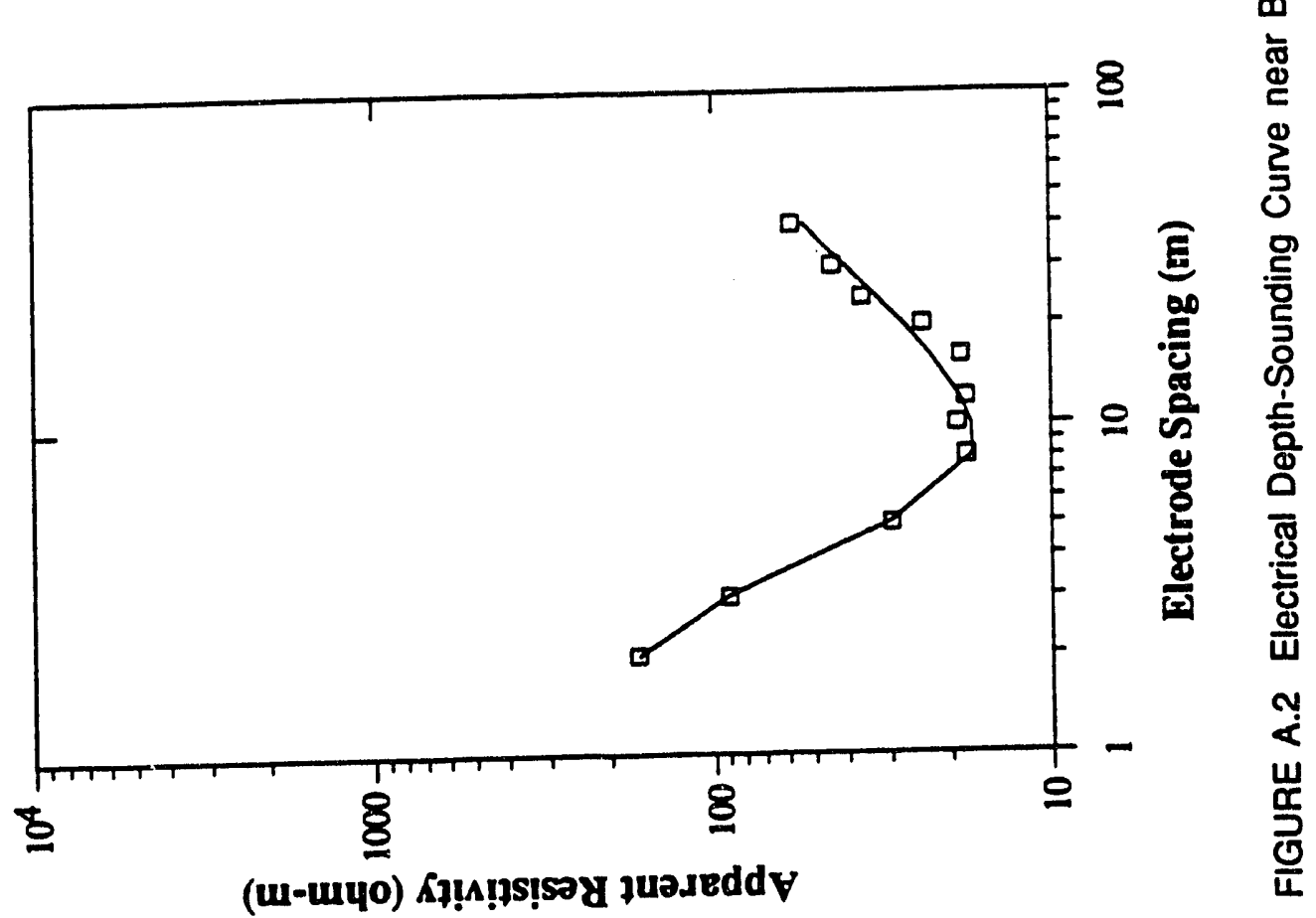



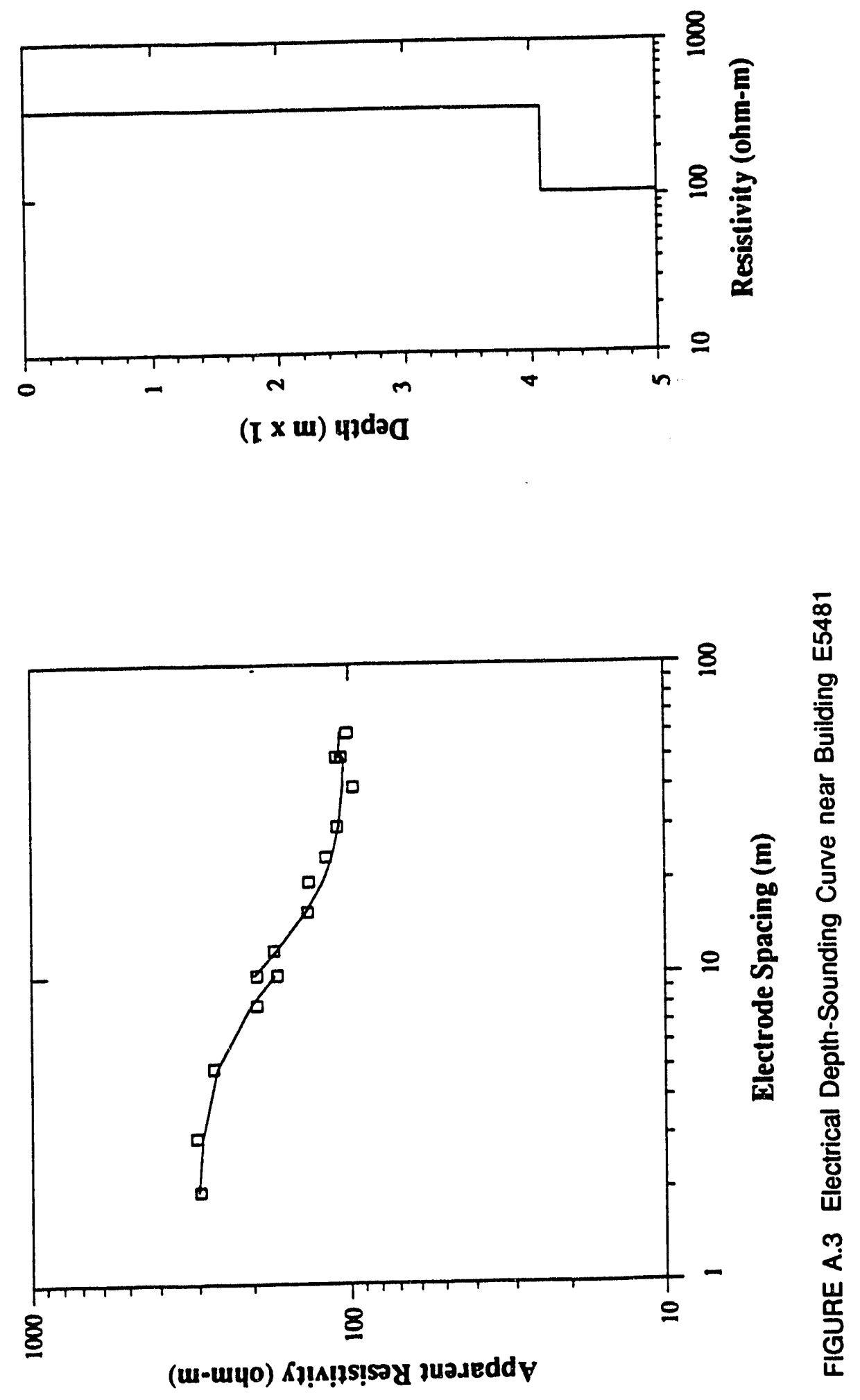

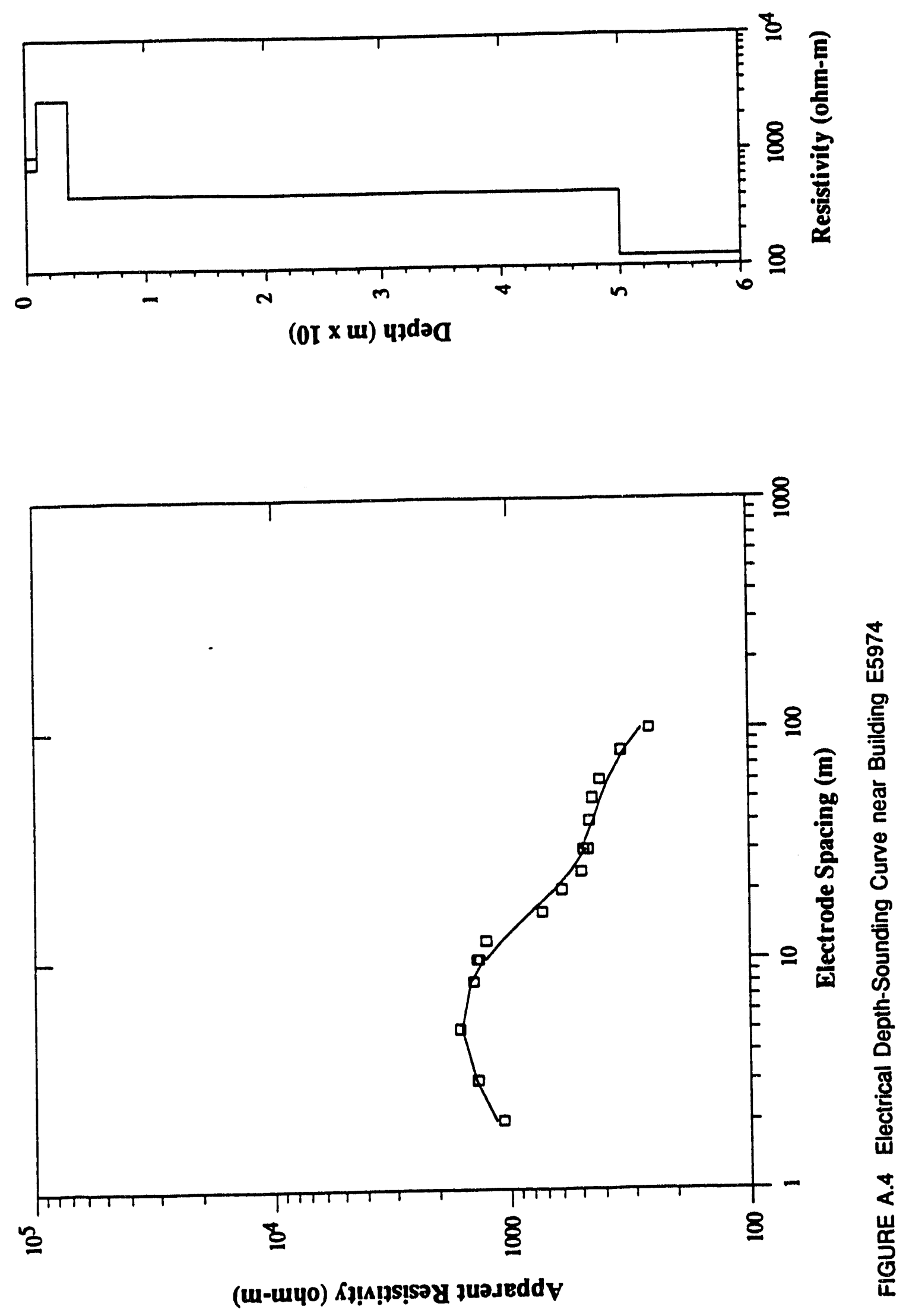
Appendix B:

Ground-Penetrating Radar Line Coordinates 
Appendix B:

Ground-Penetrating Radar Line Coordinates

\begin{tabular}{|c|c|c|c|c|}
\hline \multirow{2}{*}{$\begin{array}{l}\text { Line } \\
\text { No. }\end{array}$} & \multicolumn{2}{|c|}{$\begin{array}{c}\text { Start } \\
\text { Coordinates }\end{array}$} & \multicolumn{2}{|c|}{$\begin{array}{c}\text { End } \\
\text { Coordinates }\end{array}$} \\
\hline & North & East & North & East \\
\hline 1 & 00 & 110 & 100 & 110 \\
\hline 2 & 00 & 105 & 100 & 105 \\
\hline 3 & 00 & 100 & 100 & 100 \\
\hline 4 & 00 & 95 & 100 & 95 \\
\hline 5 & 00 & 90 & 100 & 90 \\
\hline 6 & 00 & 85 & 100 & 85 \\
\hline 7 & 00 & 80 & 100 & 80 \\
\hline 8 & 00 & 75 & 100 & 75 \\
\hline 9 & 00 & 70 & 100 & 70 \\
\hline 10 & 00 & 65 & 100 & 65 \\
\hline 11 & 00 & 60 & 100 & 60 \\
\hline 12 & 00 & 55 & 20 & 55 \\
\hline 13 & 00 & 25 & 16 & 25 \\
\hline 14 & 66 & 55 & 100 & 55 \\
\hline 15 & 70 & 50 & 100 & 50 \\
\hline 16 & 69 & 45 & 100 & 45 \\
\hline 17 & 69 & 40 & 100 & 40 \\
\hline 18 & 63 & 35 & 100 & 35 \\
\hline 19 & 63 & 30 & 100 & 30 \\
\hline 20 & 63 & 25 & 100 & 25 \\
\hline 21 & 63 & 20 & 100 & 20 \\
\hline 22 & 00 & 15 & 100 & 15 \\
\hline 23 & 00 & 10 & 100 & 10 \\
\hline
\end{tabular}

\begin{tabular}{|c|c|c|c|c|}
\hline \multirow{2}{*}{$\begin{array}{l}\text { Line } \\
\text { No. }\end{array}$} & \multicolumn{2}{|c|}{$\begin{array}{c}\text { Start } \\
\text { Coordinates } \\
\end{array}$} & \multicolumn{2}{|c|}{$\begin{array}{c}\text { End } \\
\text { Coordinates }\end{array}$} \\
\hline & North & East & North & East \\
\hline 24 & 00 & 05 & 100 & 05 \\
\hline 25 & 00 & 00 & 100 & 00 \\
\hline 26 & 100 & 00 & 100 & 110 \\
\hline 27 & 95 & 00 & 95 & 110 \\
\hline 28 & 90 & 00 & 90 & 110 \\
\hline 29 & 85 & 00 & 85 & 110 \\
\hline 30 & 80 & 00 & 80 & 110 \\
\hline 31 & 75 & 00 & 75 & 110 \\
\hline 32 & 70 & 53 & 70 & 110 \\
\hline 33 & 65 & 60 & 65 & 110 \\
\hline 34 & 60 & 63 & 60 & 110 \\
\hline 35 & 55 & 60 & 55 & 110 \\
\hline 36 & 50 & 64 & 50 & 110 \\
\hline 37 & 45 & 60 & 45 & 110 \\
\hline 38 & 40 & 60 & 40 & 110 \\
\hline 39 & 35 & 60 & 35 & 110 \\
\hline 40 & 30 & 60 & 30 & 110 \\
\hline 41 & 25 & 60 & 25 & 110 \\
\hline 42 & 20 & 59 & 20 & 110 \\
\hline 43 & 15 & 55 & 15 & 110 \\
\hline 44 & 10 & 50 & 10 & 110 \\
\hline 45 & 05 & 00 & 05 & 110 \\
\hline 46 & 00 & 00 & 00 & 110 \\
\hline
\end{tabular}



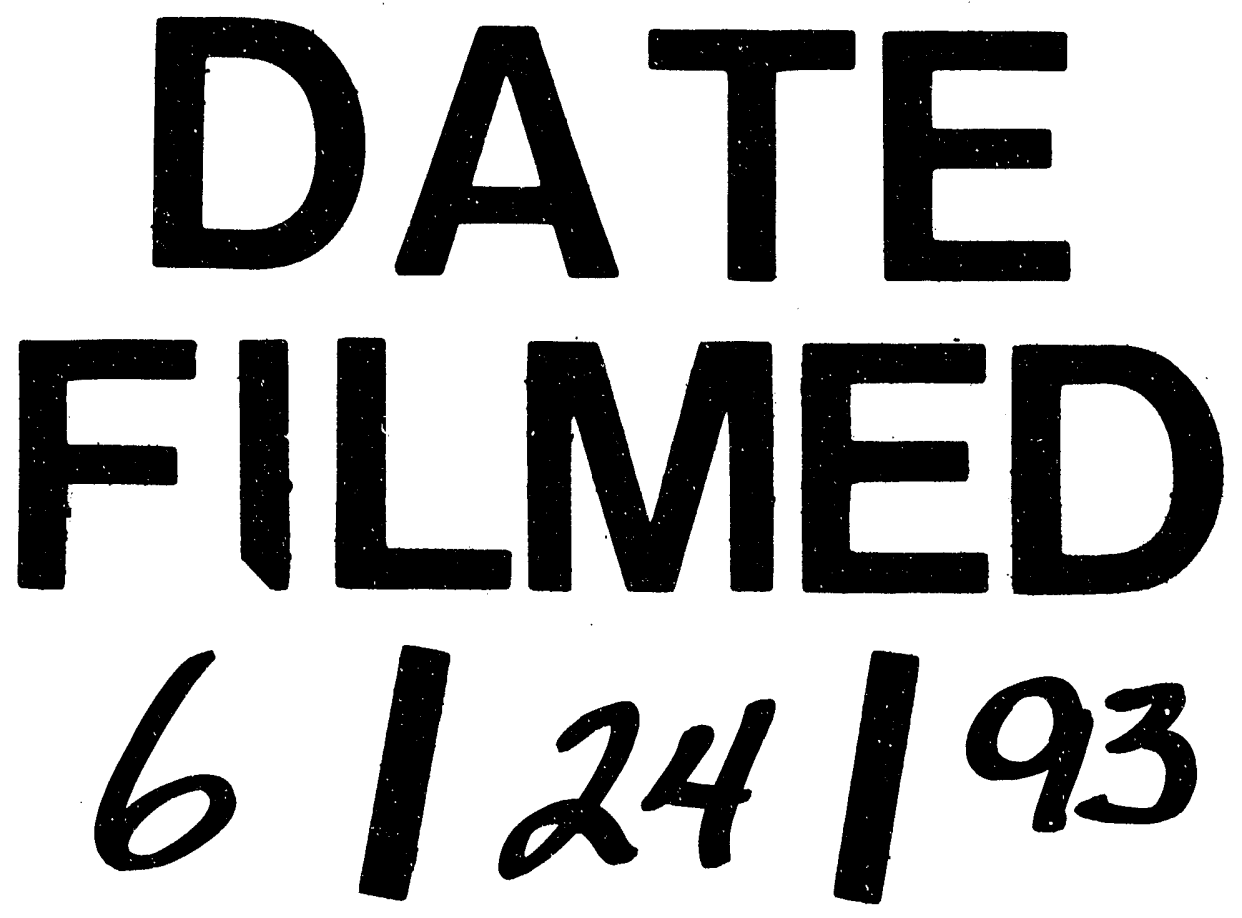